\title{
Constitutive Characteristics, Microstructure, and Texture Evolution of As-Cast 42CrMo Alloy in Nonisothermal Multipass Compression
}

\author{
Fangcheng Qin $\mathbb{D}^{1},{ }^{1}$ Huiping Qi $\mathbb{D}^{2}{ }^{2}$ Chongyu Liu, ${ }^{1}$ Haiquan Qi, ${ }^{1}$ and Zhengbing Meng ${ }^{1}$ \\ ${ }^{1}$ Key Laboratory of New Processing Technology for Nonferrous Metal \& Materials, Ministry of Education, \\ Guilin University of Technology, Guilin 541004, China \\ ${ }^{2}$ School of Materials Science and Engineering, Taiyuan University of Science and Technology, Taiyuan 030024, China
}

Correspondence should be addressed to Huiping Qi; qhp9974@tyust.edu.cn

Received 31 October 2020; Revised 1 December 2020; Accepted 18 December 2020; Published 5 January 2021

Academic Editor: Gianfranco Palumbo

Copyright ( 12021 Fangcheng Qin et al. This is an open access article distributed under the Creative Commons Attribution License, which permits unrestricted use, distribution, and reproduction in any medium, provided the original work is properly cited.

The nonisothermal multipass deformation behavior of as-cast $42 \mathrm{CrMo}$ alloy was studied with declining temperature, constant pass strain, varying strain rate, and interval time. The stresses are used to develop the constitutive model. As the finishing temperature increases from $990^{\circ} \mathrm{C}$ to $1070^{\circ} \mathrm{C}$, the stress decreases gradually and the softening effect increases, which results in a large grain size and inhomogeneous microstructure. The low angle grain boundaries transform into high angle grain boundaries through absorbing dislocations. The noticeable stress softening in a high strain rate is attributed to the thermal softening, dynamic recovery, and dynamic recrystallization. The thermal softening is no longer considered to be the main interpass softening mechanism at a low strain rate. The interval time has a negligible effect on the stress, but the significant changes in grain size and texture component are caused by the interpass softening. The average grain size is approximately $40 \mu \mathrm{m}$, and the distorted grain boundaries and small fine grains are found in the interval times of $0.5-5 \mathrm{~s}$, implying the dynamic recovery and grain growth. The near $\{001\}<110>$ and $\{110\}<112>$ orientation exerts an important influence on the grain refinement.

\section{Introduction}

$42 \mathrm{CrMo}$ alloy is widely used in the production of ring components such as bearing and flange due to the high strength, excellent fracture toughness, and abrasive resistance $[1,2]$. The $42 \mathrm{CrMo}$ ring parts are manufactured by the radial-axial hot ring rolling (RAHRR). The RAHRR is a complex process with the characteristics of nonisothermal, multipass, and accumulative deformation and so forth. The wall thickness of ring blank is gradually reduced with a progressively narrowing gap between the driven roll and mandrel. The height is controlled by feeding the upper axial roll towards the lower axial roll [3]. The continuous expansion in diameter and shape in cross section is produced.

Extensive studies on the multipass deformation behavior based on multiroll continuous rolling and multidirection forging have been conducted using compression test [4-9]. The isothermal and nonisothermal multipass compression tests of 7150 aluminum alloy were carried out, and the deformation behavior, constitutive relations, and microstructure evolutions were analyzed in detail [4]. The microstructure evolution of 2519 aluminum alloy was studied using isothermal multipass compression and verified that the recrystallization fraction increased with increasing pass numbers [5]. The stress decreased with increasing finishing temperature during 7-pass compression [6], and the subgrains transformed into the grains with straight grain boundaries. The effect of grain size on mechanical properties of CrMo thick plate was predicted by multipass deformation [7]. The evolution of grain size of F40 ship plate steel was also studied by multipass deformation and indicated that the degree of grain refinement increased with increasing pass numbers [8]. The mechanisms of grain refinement in $\mathrm{Cu}-\mathrm{Cr}-\mathrm{Zr}$ alloy at different multiaxial forging temperatures were revealed, and then the grain orientation was determined [9]. However, there are few studies focusing on the 
multipass deformation in RAHRR, especially the rolling based on as-cast ring blank. The as-cast ring blank is hotrolled directly to the required geometrical dimension, and both the thermoplasticity and mechanical properties are improved in RAHRR. The process has some advantages including saving material and energy, reducing times of heating, and low emission [10]. The dynamic and static recrystallizations occur in radial and axial roll gaps, while the metadynamic recrystallization plays a dominant role outside deformation areas in RAHRR. The metadynamic recrystallization behavior of $42 \mathrm{CrMo}$ alloy was studied to reveal the response of grain refinement to deformation parameters [11]. The effects of temperature and interval time on the microstructure of as-cast $42 \mathrm{CrMo}$ alloy were also clarified using interrupted isothermal compression [12]. In addition, for industry multipass processing, the nonisothermal process is always undergone with gradually declining temperature $[4,13]$. The interaction between hardening and softening effects of as-cast $42 \mathrm{CrMo}$ alloy in RAHRR presents the complicated microstructure and texture evolution. The microstructure and texture are affected by the discontinuous characteristics in deformation intervals during multipass rolling [14-16]. The grain refinement and size distribution are also closely related to the texture evolution. The softening behavior under interpass deformation results in some distinct differences when compared with that under single-pass continuous compression. Thus, it is critical to clarify the mechanisms of stress softening and grain refinement in discontinuous multipass compression first.

In this study, the nonisothermal multipass compression of as-cast $42 \mathrm{CrMo}$ ally was performed on a Gleeble-3500 thermal simulator, and the effects of finishing temperature, strain rate, and interval time on the stress, microstructure, and texture were studied. The corresponding constitutive model was established. The softening behavior and microstructure evolution mechanism were clarified in detail by electron backscatter diffraction (EBSD) and transmission electron microscopy (TEM) techniques. The results will provide new insights for the microstructure control and parameter optimization in RAHRR.

\section{Material and Experimental Procedure}

A commercial $42 \mathrm{CrMo}$ alloy with the main chemical composition (wt.\%) of $0.44 \mathrm{C}, 0.28 \mathrm{Si}, 0.72 \mathrm{Mn}, 1.13 \mathrm{Cr}$, $0.22 \mathrm{Mo}, 0.012 \mathrm{P}, 0.007 \mathrm{~S}, 0.15 \mathrm{Ni}, 0.12 \mathrm{Cu}$, and (bal.) Fe was used in this study. The as-cast ring blank with the dimensions of $240 \mathrm{~mm}$ in outer diameter, $120 \mathrm{~mm}$ in inner diameter, and $45 \mathrm{~mm}$ in height was prepared by sand-casting process $[17,18]$. In the sand casting, a pouring temperature of $1530-1540^{\circ} \mathrm{C}$ and a pouring rate of $16.8-18.5 \mathrm{~kg} / \mathrm{s}$ were selected. The average grain size is approximately $87 \mu \mathrm{m}$, as shown in Figure 1. Cylindrical specimens with a diameter of $10 \mathrm{~mm}$ and a height of $15 \mathrm{~mm}$ were machined from the same radial positions of the ring blank to guarantee the uniformity of microstructure [19]. The nonisothermal multipass (5 passes, continuous cooling) compression tests were carried out on a Gleeble-3500 thermal simulator at the initial temperature of $1150^{\circ} \mathrm{C}$. Figure 2 shows the detailed

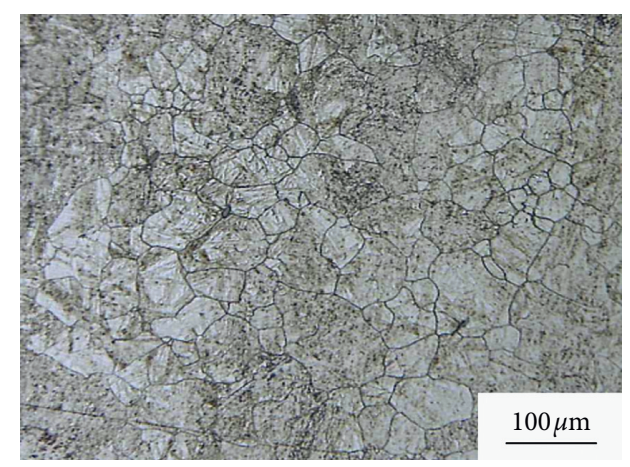

FIgURE 1: The initial microstructure of as-cast 42CrMo ring blank [18].

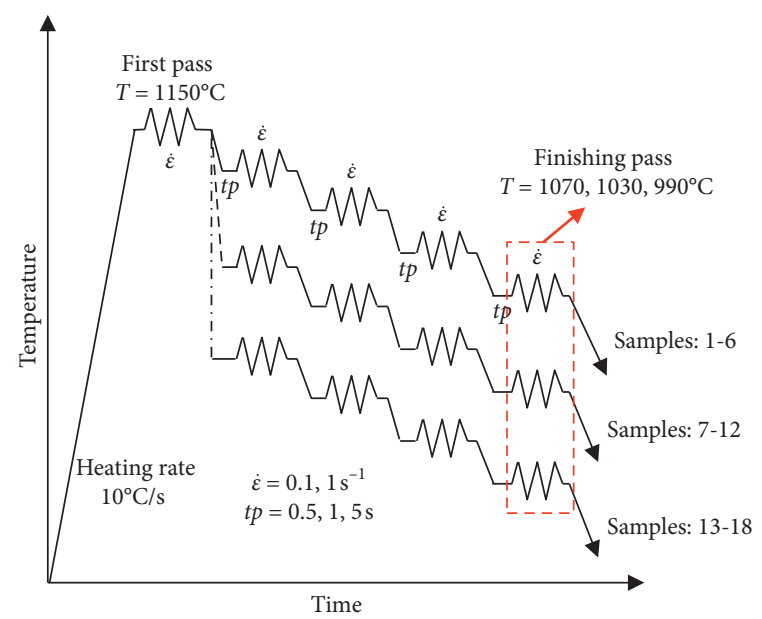

FIGURE 2: The detailed experimental processes of hot compression tests.

experimental processes of hot compression tests. Before compression, all specimens were heated to $1150^{\circ} \mathrm{C}$ at a heating rate of $10^{\circ} \mathrm{C} / \mathrm{s}$ and soaked for $2 \mathrm{~min}$ to eliminate thermal gradients. The finishing temperatures of $1070^{\circ} \mathrm{C}$, $1030^{\circ} \mathrm{C}$, and $990^{\circ} \mathrm{C}$ and the corresponding temperature decrements of $20^{\circ} \mathrm{C}, 30^{\circ} \mathrm{C}$, and $40^{\circ} \mathrm{C}$ in interpasses were applied, respectively. The true strain of 0.183 in each pass and interval times (tp) of $0.5 \mathrm{~s}, 1 \mathrm{~s}$, and $5 \mathrm{~s}$ are used. The strain rates were $0.1 \mathrm{~s}^{-1}$ and $1 \mathrm{~s}^{-1}$. The specimen numbers and detailed deformation parameters are listed in Table 1. The nonisothermal multipass compression tests are similar to the methods of Qin et al. 2016 [19], but the strain rate and interval time are selected as the variables to study their effect on the flow behavior in this study. The graphite foils with a thickness of $0.5 \mathrm{~mm}$ were positioned between the specimen and anvils to reduce the contact friction [20]. A thermocouple was welded to the center of each sample to allow the temperature to be tracked and the load-stroke data to be collected with accuracy [21]. Then, the specimen was compressed at the selected parameters. To retain the deformed microstructure, all the specimens were immediately water-quenched to ambient temperature.

True stress-strain curves were recorded automatically using the standard equations from the load-stroke data 
TABLE 1: Deformation parameters of the nonisothermal multipass compression tests.

\begin{tabular}{|c|c|c|c|c|}
\hline Sample no. & Finishing temperature $\left({ }^{\circ} \mathrm{C}\right)$ & Strain rate $\left(\mathrm{s}^{-1}\right)$ & Intervals time $(\mathrm{s})$ & Temperature decrement $\left({ }^{\circ} \mathrm{C}\right)$ \\
\hline 1 & 1070 & 0.1 & 0.5 & 20 \\
\hline 2 & & 1 & & \\
\hline 3 & & 0.1 & 1 & \\
\hline 4 & & 1 & & \\
\hline 5 & & 0.1 & 5 & \\
\hline 6 & & 1 & & \\
\hline 7 & 1030 & 0.1 & 0.5 & 30 \\
\hline 8 & & 1 & & \\
\hline 9 & & 0.1 & 1 & \\
\hline 10 & & 1 & & \\
\hline 11 & & 0.1 & 5 & \\
\hline 12 & & 1 & & \\
\hline 13 & 990 & 0.1 & 0.5 & 40 \\
\hline 14 & & 1 & & \\
\hline 15 & & 0.1 & 1 & \\
\hline 16 & & 1 & & \\
\hline 17 & & 0.1 & 5 & \\
\hline 18 & & 1 & & \\
\hline
\end{tabular}

measured in these compression tests [22]. The specimens were sectioned parallel to the longitudinal compression axis. The section was ground, polished, and etched in a solution of saturated picric acid. The microstructures were observed by VHX-600E optical microscopy. The average grain sizes were measured using the line intercept method. The texture was determined by EBSD system equipped at a FEI Nano 430 field-emission scanning electron microscopy (SEM). The EBSD specimens were electropolished in a solution of $5 \%$ perchloric acid and $95 \%$ ethyl alcohol at $30 \mathrm{~V}$ and $20^{\circ} \mathrm{C}$. Thin foils for TEM were prepared by mechanical polishing to a thickness of about $60 \mu \mathrm{m}$ followed by double-jet electropolishing in a solution of $10 \%$ perchloric acid and $90 \%$ acetic acid at $10 \mathrm{~V}$ and $-25^{\circ} \mathrm{C}$. TEM observations were performed on a FEI Tecnai G2 F20 transmission electron microscopy operating at $200 \mathrm{kV}$.

\section{Results and Analysis}

3.1. Multipass Flow Behavior. According to the results of isothermal compression $[10,12,23,24]$, nonisothermal multipass compression tests were carried out to simulate industry multipass processing more precisely. Figures 3(a)3(c) show the true stress-strain curves and temperature curves of as-cast $42 \mathrm{CrMo}$ alloy at different finishing temperatures. The stress increases with increasing strain rate, while it decreases with increasing finishing temperature at a given initial temperature. They imply that the stress is sensitive to the strain rate and finishing temperature during nonisothermal multipass deformation. Rising stress curves and decreasing pass temperature across the cumulative strain with increasing passes number are all presented in Figure 3. The rise in stress is not only the declining temperature effect but also the more prevalent retained deformed regions [25]. In addition, at the same finishing temperature and strain rate, the stresses in each pass do not show significant change with the interval time. However, under diminishing temperature conditions with the constant pass true strain of 0.183 , the interpass softening is enhanced at the interval time of $5 \mathrm{~s}$. This result is dissimilar to that under the isothermal multipass deformation; that is, longer interval time causes less softening [21]. The flow softening during nonisothermal multipass deformation is the net result of microstructure softening by recrystallization and hardening by accumulative strain; therein, the flow hardening is due to the decrease in temperature. At the high strain rate of $1 \mathrm{~s}^{-1}$, the decreasing stress occurs after peak stress in each pass, which might be strongly depending on the thermal softening [26]. The variations of peak stresses with finishing temperature at interval time of $1 \mathrm{~s}$ are compared under the same pass number, as shown in Figure 3(d). It can also be found that, for a constant strain rate, the peak stress increases gradually with increasing passes number. The difference in peak stress of different finishing temperature is inconspicuous at the smaller passes number $(\leq 2)$, but it increases with increasing passes number. For example, under the strain rate of $0.1 \mathrm{~s}^{-1}$ and finishing temperatures of $990^{\circ} \mathrm{C}$ and $1070^{\circ} \mathrm{C}$, the difference value of peak stress increases from $0.8 \mathrm{MPa}$ at 1 pass to $22 \mathrm{MPa}$ at 5 passes. It is mainly due to the fact that the static recrystallization (SRX) becomes weakened during the interpass. The peak stress in each pass rises compared with the one under the true stain of 0.183 . The mixed microstructures and new grains in all passes are similar to those in the isothermal conditions. But the shapes of the nonisothermal stress curves considerably differ from those under isothermal stress curves [26].

3.2. Constitutive Characteristics. Nonisothermal multipass stresses have been used to derive the constitutive models, which have been further applied to multistage simulations of a declining temperature rolling schedule [4, 27-29]. The effect of temperature and strain rate on the stress is described by the Zener-Hollomon parameter $(Z)$ according to the following equations $[30,31]$ : 


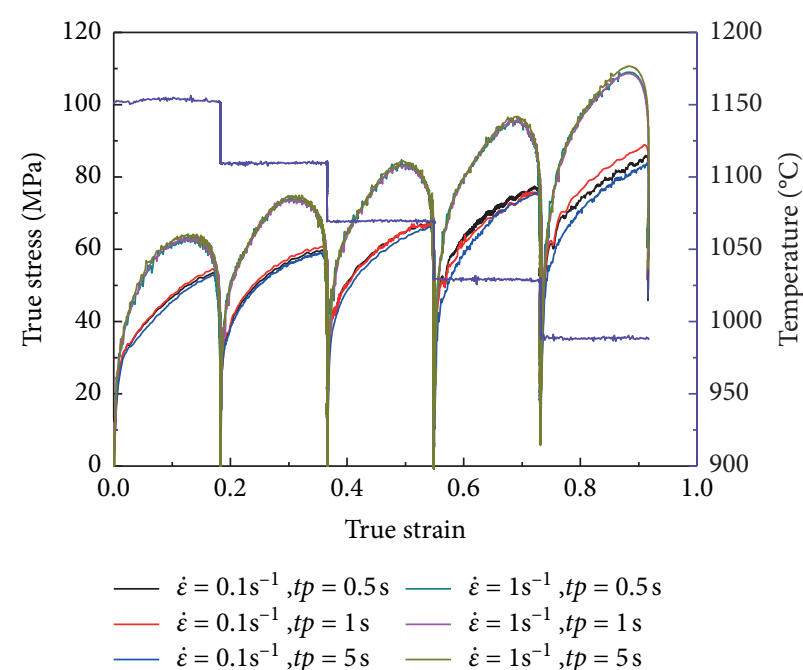

(a)

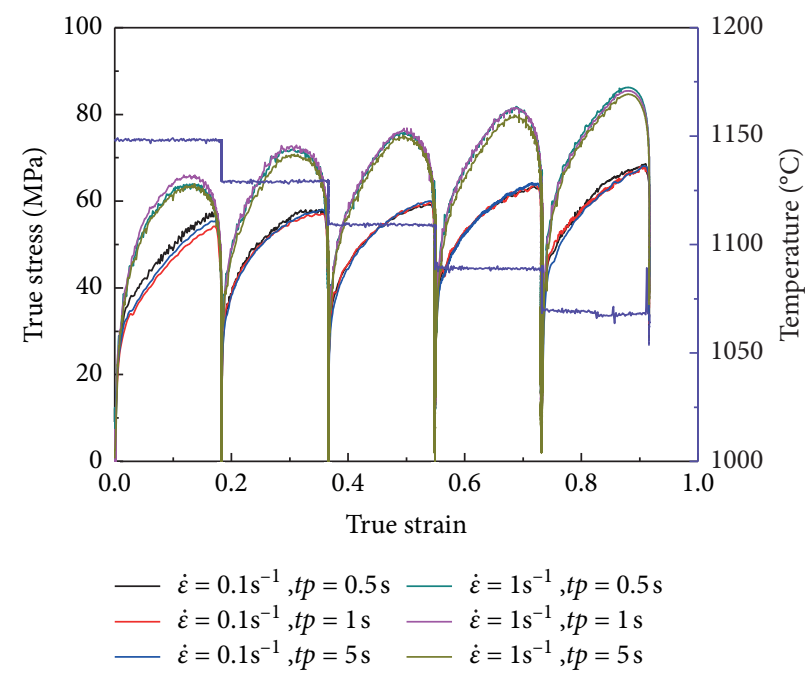

(c)

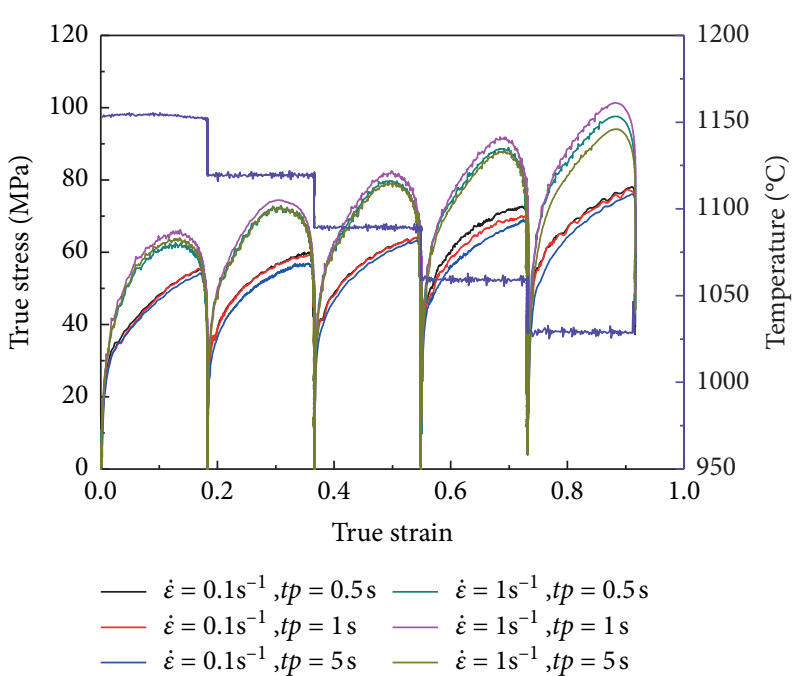

(b)

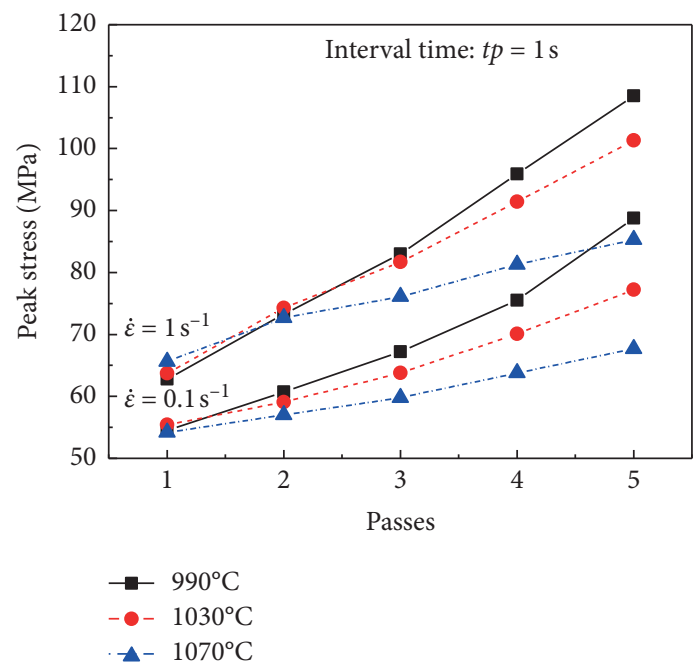

(d)

Figure 3: True stress-strain curves of as-cast $42 \mathrm{CrMo}$ alloy at different finishing temperatures of (a) $990^{\circ} \mathrm{C}$, (b) $1030^{\circ} \mathrm{C}$, (c) $1070^{\circ} \mathrm{C}$, and (d) peak stress of each pass during nonisothermal multipass compression.

$$
\begin{aligned}
& Z=\dot{\varepsilon} \exp \left(\frac{Q}{R T}\right)=F_{1}(\sigma)=A_{1} \sigma^{n_{1}}, \\
& Z=F_{2}(\sigma)=A_{2} \exp (\beta \sigma), \\
& Z=F(\sigma)=A[\sin h(\alpha \sigma)]^{n},
\end{aligned}
$$

where $\sigma$ is the stress $(\mathrm{MPa}) ; \dot{\varepsilon}$ is the strain rate $\left(\mathrm{s}^{-1}\right)$; $Q$ is the activation energy $(\mathrm{kJ} / \mathrm{mol}) ; T$ is the absolute temperature $(\mathrm{K})$; $R$ is the universal gas constant $(8.314 \mathrm{~J} / \mathrm{mol} \cdot \mathrm{K}) ; A, A_{1}$, and $A_{2}$ are the material constants $\left(\mathrm{s}^{-1}\right) ; \beta$ and $\alpha$ are also the material constants $\left(\mathrm{MPa}^{-1}\right) ; n$ and $n_{1}$ are the stress exponents, and $\alpha$ is calculated as $\alpha=\beta / n_{1}$. Equations (1)-(3) are suitable for a low stress level $(\alpha \sigma<0.8)$, a high stress level $(\alpha \sigma>1.2)$, and a wide range of stress level, respectively. Then, $\beta$ and $n_{1}$ are taken as the average values of the slopes of the $\ln \dot{\varepsilon}$ versus $\sigma$ plots and $\ln \dot{\varepsilon}$ versus $\ln \sigma$ plots at a series of temperatures, respectively. According to our previous results [24], $\alpha=0.00785 \mathrm{MPa}^{-1}$ is adopted in this study.

The relationship between stress and strain rate is given by substituting equation (1) into (3):

$$
\dot{\varepsilon}=A \cdot[\sin h(\alpha \sigma)]^{n} \exp \left[\frac{-Q}{R T}\right] .
$$

The natural logarithm and partial differential of both sides of equation (4) are performed, respectively, to derive the values of $n$ and $Q$ :

$$
\begin{aligned}
& \ln \sin h(\alpha \sigma)=\left(\frac{1}{n}\right) \ln \dot{\varepsilon}+\frac{Q}{n R T}-\left(\frac{1}{n}\right) \ln A \\
& Q=R\left[\frac{\partial \ln \dot{\varepsilon}}{\partial \ln [\sin h(\alpha \sigma)]}\right]_{T}\left[\frac{\partial \ln [\sin h(\alpha \sigma)]}{\partial(1 / T)}\right]_{\dot{\varepsilon}}=R n S .
\end{aligned}
$$




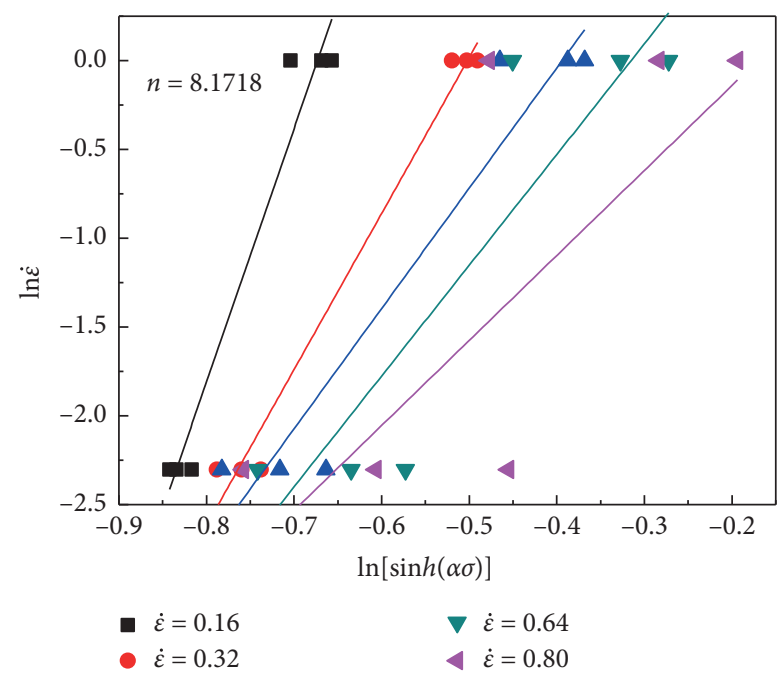

(a)

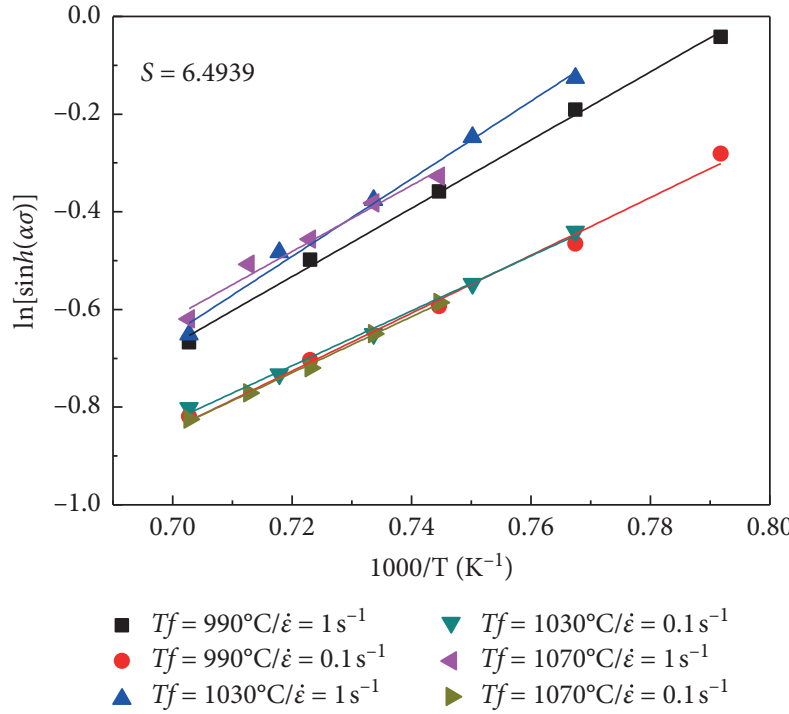

(b)

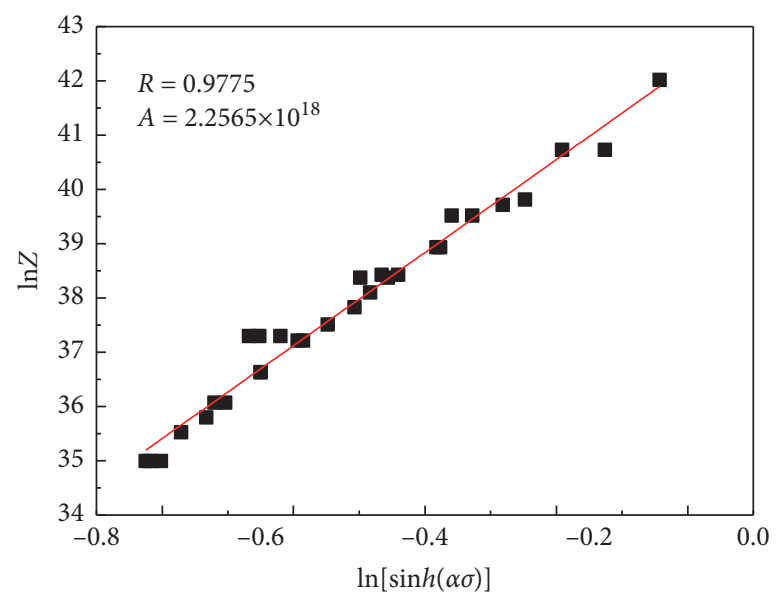

(c)

Figure 4: Correlations between (a) $\ln \dot{\varepsilon}-\ln [\sin h(\alpha \sigma)]$, (b) $\ln [\sin h(\alpha \sigma)]-(1 / T)$, and (c) $\ln Z-\ln [\sin h(\alpha \sigma)]$ during nonisothermal multipass compression.

According to the stress curves during nonisothermal multipass compression, $n$ and $Q$ are derived by equations (5) and (6). $n$ is the average slope of $\ln \dot{\varepsilon}$ versus $\ln [\sin h(\alpha \sigma)]$ plots and $S$ is the average slope of $\ln [\sin h(\alpha \sigma)]$ versus $(1 / T)$ plots, as shown in Figures 4(a) and 4(b). The values of $n$ and $Q$ are calculated as 8.1718 and $441.198 \mathrm{KJ} / \mathrm{mol}$, respectively. In addition, taking the natural logarithm of both sides of equation (3), $A$ is expressed as follows:

$$
\ln Z=\ln A+n \ln \sinh (\alpha \sigma) .
$$

The values of $Z$ at different temperatures and strain rates are calculated by equation (1). $\ln A$ is the intercept of $\ln Z$ versus the $\ln [\sin h(\alpha \sigma)]$ plot. It is found from Figure 4(c) that the value of $A$ is given as $2.2565 \times 10^{18} \mathrm{~s}^{-1}$. Figure $4(\mathrm{c})$ also indicates a good linear relationship between $\ln Z$ and $\ln [\sin h(\alpha \sigma)]$ with correlation coefficient $R$ being approximately 0.9775 . Thus, equation (8) is the established constitutive model of as-cast $42 \mathrm{CrMo}$ alloy based on the nonisothermal multipass deformation.

$$
\dot{\varepsilon}=2.2565 \times 10^{18} \cdot[\sin h(0.00785 \sigma)]^{8.1718} \exp \left[\frac{-441198}{R T}\right]
$$

3.3. Microstructural Characterization and Texture Evolution. Except for the difference in the stress curves, the microstructure is the main characteristic of the nonisothermal deformation over the isothermal process [32]. Figure 5 shows the microstructures of as-cast $42 \mathrm{CrMo}$ alloy at different nonisothermal multipass deformation conditions. At the high finishing temperature of $1070^{\circ} \mathrm{C}$ and interval time of $0.5 \mathrm{~s}$, the large average grain sizes are found regardless of strain rate. In these conditions, the grains approximately $73 \mu \mathrm{m}$ in diameter at the strain rate of $0.1 \mathrm{~s}^{-1}$ are slightly larger compared with those at the strain rate of $1 \mathrm{~s}^{-1}$, as presented in Figures 5(a) and 5(b). At the finishing temperature of $1030^{\circ} \mathrm{C}$ and strain rate of $1 \mathrm{~s}^{-1}$, the grain sizes increase gradually as the interval time increases from $0.5 \mathrm{~s}$ to 


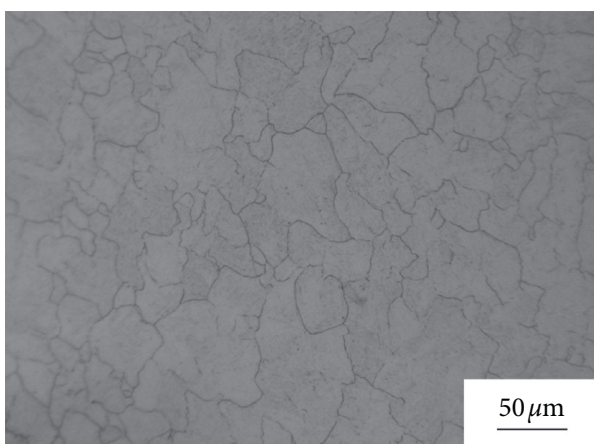

(a)

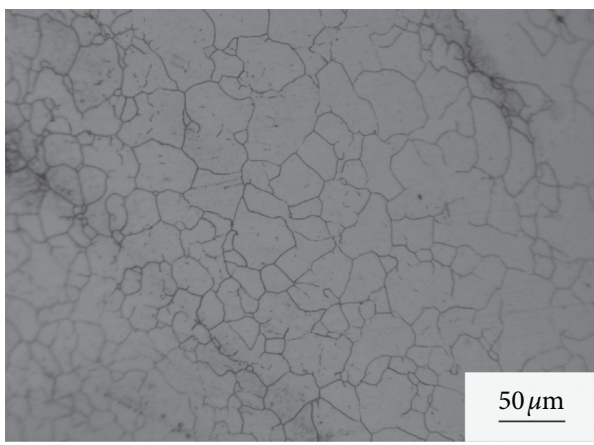

(c)

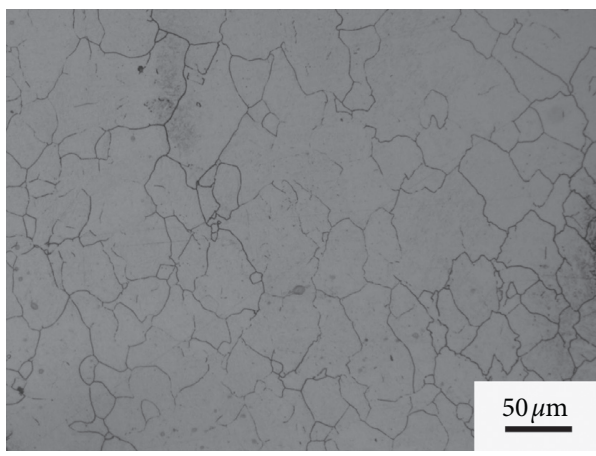

(e)

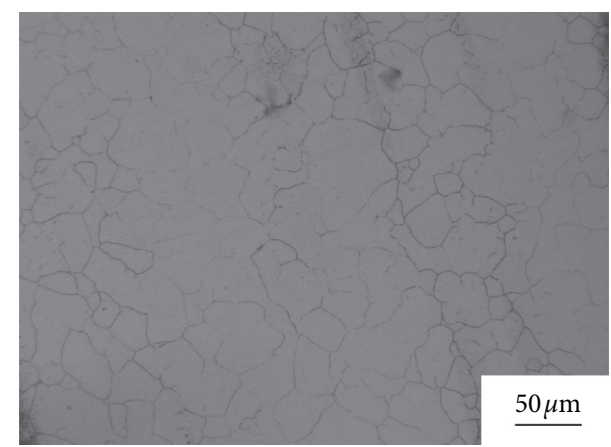

(b)

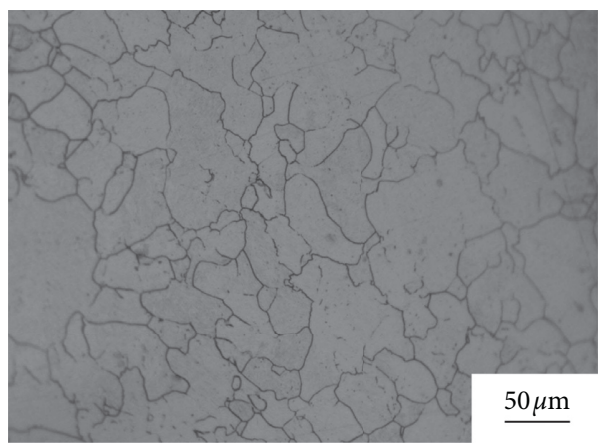

(d)

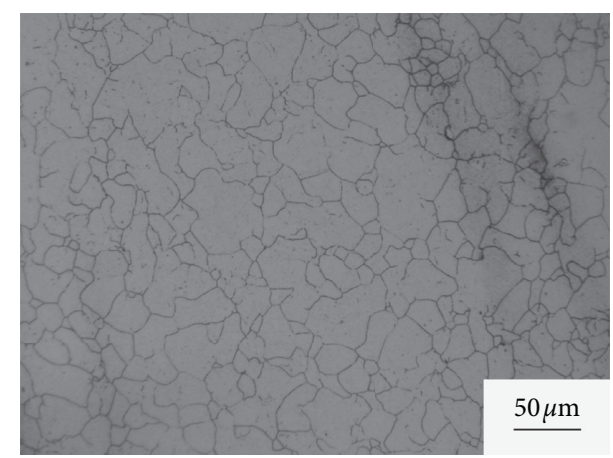

(f)

Figure 5: Microstructures of as-cast 42CrMo alloy at different nonisothermal deformation conditions: (a) sample 1; (b) sample 2; (c) sample 8; (d) sample 10; (e) sample 12; (f) sample 14.

$5 \mathrm{~s}$. The DRX occurs at the interval time of $0.5 \mathrm{~s}$, which results in the finer and homogeneous distribution grains with the average size being approximately $40 \mu \mathrm{m}$. In addition, the DRV and grain growth are dominated at the interval times of $1 \mathrm{~s}$ and $5 \mathrm{~s}$. The distorted grain boundaries and small fine grains are found in Figures 5(d) and 5(e). This may be related to the larger grains growing with high activity at the expense of suppressing the smaller DRX fine grains. It also can be seen from Figure 5(f) that the microstructure is similar to that in Figure 5(c). The low finishing temperature of $990^{\circ} \mathrm{C}$ leads to the more fine and homogeneous grain approximately $35 \mu \mathrm{m}$ in diameter when compared with that under the finishing temperatures of $1030^{\circ} \mathrm{C}$ and $1070^{\circ} \mathrm{C}$.

In the nonisothermal multipass compression, the grain refinement and texture evolution are affected by the finishing temperature, interval time, and strain rate. EBSD data was analyzed with postprocessing TSL-OIM software. The different textures extracted from $\varphi_{2}=45^{\circ}$ sections of orientation distribution functions (ODFs) were discussed. Figure 6 shows the texture evolution of as-cast 42CrMo alloy under different nonisothermal multipass compression conditions. At the finishing temperature of $1070^{\circ} \mathrm{C}$ and interval time of $0.5 \mathrm{~s}$, the texture is mainly composed of $\{113\}$ $<110>,\{001\}<110>$ and $\{111\}<110>$ orientations at the strain rate of $0.1 \mathrm{~s}^{-1}$, while it is characterized by near (111)

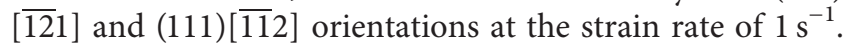
The intensities of $\{113\}<110>$ and (111)[112] are 4.8 and 5.0, respectively. The former represents a typical rolling texture and the latter indicates a recrystallization texture, which is consistent with the large average grain sizes shown in Figures 5(a) and 5(b). At the finishing temperature of $1030^{\circ} \mathrm{C}$ and strain rate of $1 \mathrm{~s}^{-1}$, the texture components show significant change with increasing interval time. The recrystallization texture (111)[112] still exists, but the intensity is 


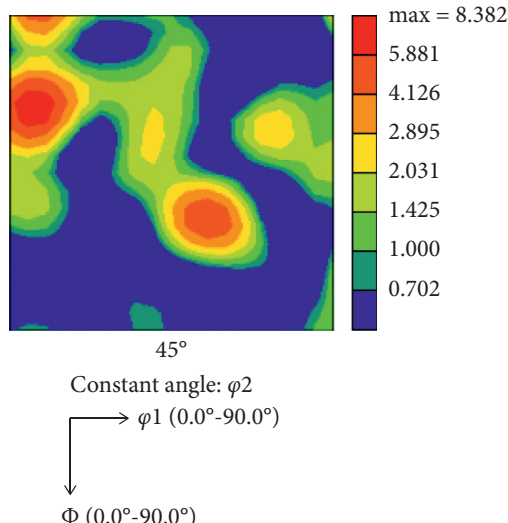

(a)

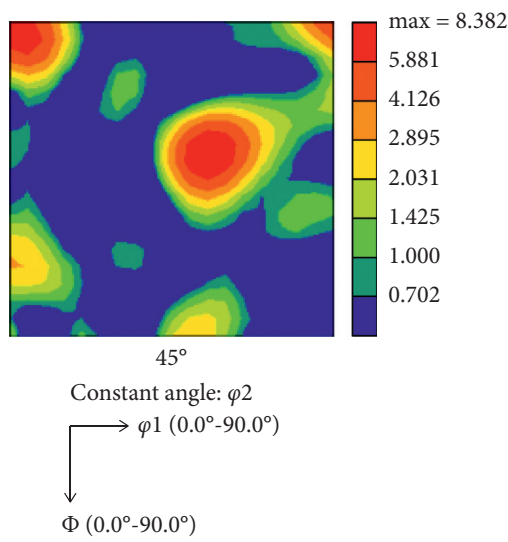

(d)

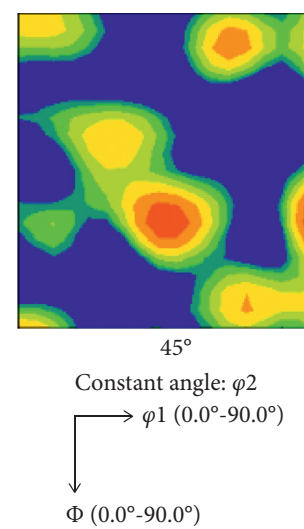

(b)

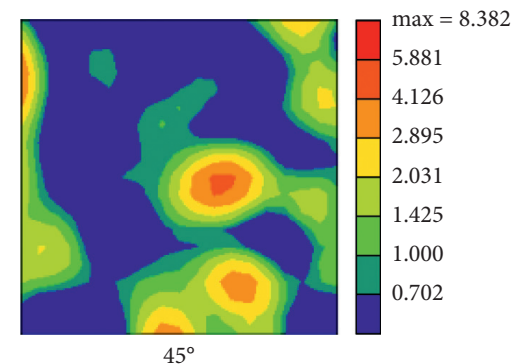

Constant angle: $\varphi 2$

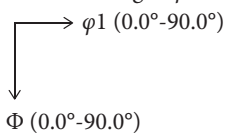

(e)

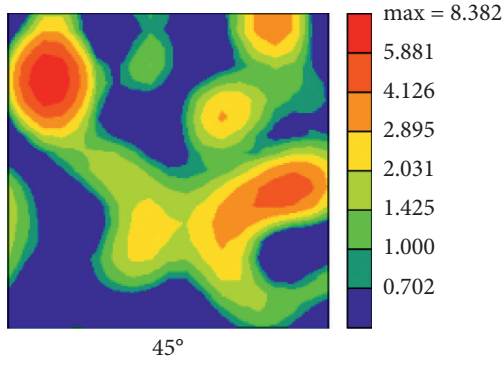

Constant angle: $\varphi 2$

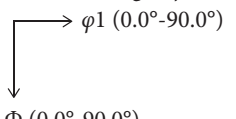

(c)

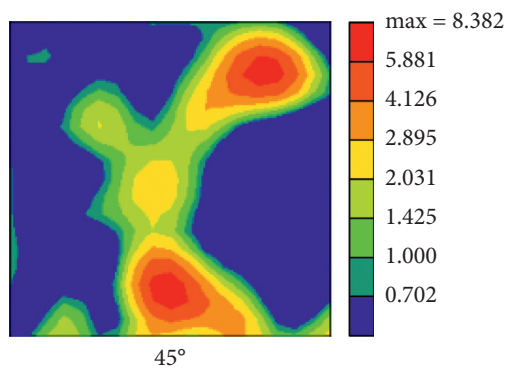

Constant angle: $\varphi 2$

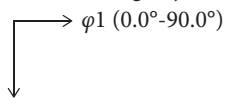

$\Phi\left(0.0^{\circ}-90.0^{\circ}\right)$

(f)

Figure 6: $\varphi_{2}=45^{\circ}$ sections of ODFs of as-cast 42CrMo alloy at different nonisothermal deformation conditions: (a) sample 1; (b) sample 2; (c) sample 8; (d) sample 10; (e) sample 12; (f) sample 14.

relatively weak at the interval time of $0.5 \mathrm{~s}$, as presented in Figure 6(c). In addition, the near $\{114\}<110>$ component is also found in this condition. As the interval time increases to $1 \mathrm{~s}$, the main texture component transforms to rolling texture $\{001\}<110>$ with intensity of 5.2 , which results in a very low nucleation rate for the new recrystallization grain. When the interval time is $5 \mathrm{~s}$, the texture component is characterized by $\gamma^{\prime}$-fibre and further the intensity is reduced. Therefore, the texture evolution in Figures 6(c)-6(e) is in line with the results of microstructure illustrated in Figures $5(\mathrm{c})-5(\mathrm{e})$. At the low finishing temperature of $990^{\circ} \mathrm{C}$, the near $\{001\}<110>$ and $\{110\}<112>$ orientations are found, as shown in Figure 6(f). $\{110\}<112>$ with intensity of 4.8 represents the shear texture, which might also have an important influence on grain refinement. The results are consistent with the fine and homogeneous distribution in grain size, as presented in Figure 5(f).

Underlying the mechanical behavior is the microstructure evolution, which depends on the mechanisms and controls the final mechanical properties [27]. In RAHRR, the accumulated deformation is almost the result of dislocation motion, leading to considerable interpass softening in grain boundaries sliding and strain hardening in the elongated grains. The refined grains with a high dislocation density are found in Figures 5(f) and 7(a). The microstructure is characterized by an unstable state with high dislocation density and serious lattice distortion. As the finishing temperature increases, the stored energy is consumed by the softening effect during the interpass. The nucleation rate of recrystallization decreases because of decreasing energy and driving force. However, the grain size increases gradually with increasing finishing temperature. It can be seen from Figures 7(a) and 7(b) that the low angle grain boundaries (LAGBs) transform into high angle grain boundaries (HAGBs) through absorbing dislocations, resulting in the decrease in dislocation density. It can be concluded that rising temperature increases the DRV and recrystallization rate and thereby decreases the density of dislocations and hence reduces the driving force for recrystallization $[25,33]$. However, it is evident that its opposing effect of accelerating the rearrangements was involved in nucleation and migration of grain boundaries [25, 34-36]. These results are closely related to the stress softening at the high strain rate of $1 \mathrm{~s}^{-1}$, as shown in Figure 3. The grains grow through the migration of dislocations and HAGBs. The dominant softening mechanisms are attributed to the combined effect of thermal softening, DRV, and DRX. As the strain rate decreases to $0.1 \mathrm{~s}^{-1}$, the dislocation density is further reduced and the fraction of HAGBs is increased, as presented in Figure 7(c). However, the thermal softening is no longer 


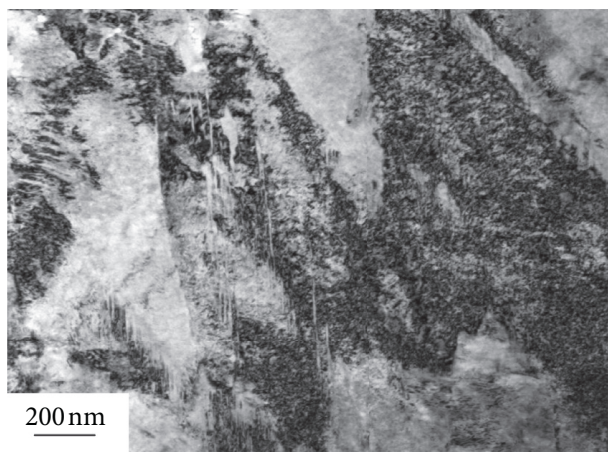

(a)

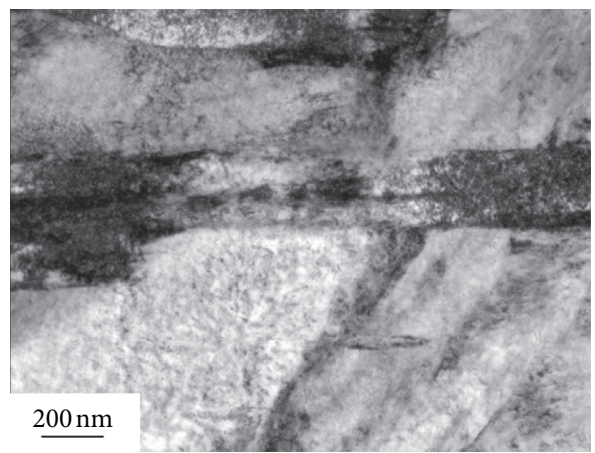

(b)

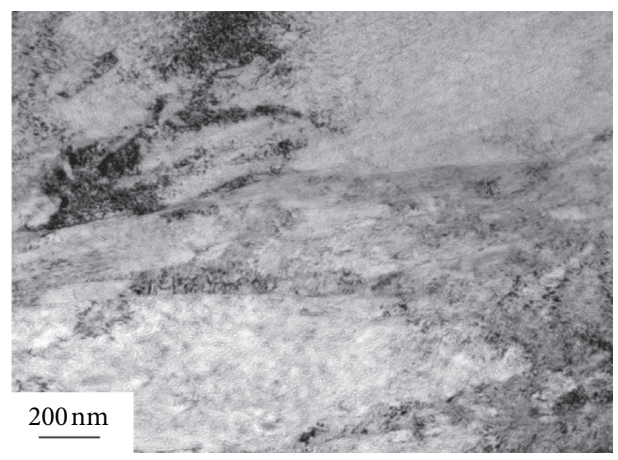

(c)

Figure 7: TEM microstructures of as-cast 42CrMo alloy during nonisothermal compression conditions: (a) sample 14; (b) sample 8; (c) sample 7 .

considered to be the main interpass softening mechanism at a low strain rate of $0.1 \mathrm{~s}^{-1}$. Moreover, previous multistage testing shows that as the interval is decreased, softening declines so that the stress becomes almost coincident with the single-stage continuous deformation for isothermal tests and for declining temperature tests $[25,37]$. This arises in the stress within the interval time of $0.5 \mathrm{~s}$ preventing any static restoration [38].

\section{Conclusions}

The nonisothermal multipass deformation behavior of ascast $42 \mathrm{CrMo}$ alloy was studied and the corresponding constitutive model was derived. The softening behavior and microstructure evolution mechanism were clarified in detail. The main conclusions are drawn as follows:

(1) As the finishing temperature increases from $990^{\circ} \mathrm{C}$ to $1070^{\circ} \mathrm{C}$, the stress decreases gradually and the softening effect increases, which results in a large grain size and inhomogeneous microstructure. The LAGBs transform into HAGBs through absorbing dislocations.

(2) The stress softening in a high strain rate is attributed to the thermal softening, DRV, and DRX. The thermal softening is no longer considered to be the main interpass softening mechanism at a low strain rate. The near $\{001\}<110>$ and $\{110\}<112>$ orientation exerts an important influence on the grain refinement.
(3) The interval time has a negligible effect on the stress, but the significant changes in grain size and texture component are caused by the interpass softening. The average grain size is approximately $40 \mu \mathrm{m}$ and both the distorted grain boundaries and small fine grains are found in the interval times of $0.5-5 \mathrm{~s}$, implying the DRV and grain growth.

\section{Data Availability}

The experimental data used to support the findings of this study are included within the article.

\section{Conflicts of Interest}

The authors declare that there are no conflicts of interest regarding the publication of this paper.

\section{Acknowledgments}

The authors are grateful for the financial support of the National Natural Science Foundation of China (no. 51875383), the Natural Science Foundation of Guangxi (nos. 2019GXNSFAA245051 and 2018GXNSFBA281056), the Science and Technology Major Project of Guangxi (no. 2018AA23004), and the Open Funding of Key Laboratory of New Processing Technology for Nonferrous Metal and Materials, Ministry of Education/Guangxi Key Laboratory of Optical and Electronic Materials and Devices (nos. 20AA-8 and 20KF-7). 


\section{References}

[1] Y. C. Lin, M.-S. Chen, and J. Zhong, "Constitutive modeling for elevated temperature flow behavior of 42CrMo steel," Computational Materials Science, vol. 42, no. 3, pp. 470-477, 2008.

[2] D. Chaouch, S. Guessasma, and A. Sadok, "Finite element simulation coupled to optimisation stochastic process to assess the effect of heat treatment on the mechanical properties of $42 \mathrm{CrMo} 4$ steel," Materials \& Design, vol. 34, pp. 679-684, 2012.

[3] F.-c. Qin, Y.-t. Li, H.-p. Qi, and L. Ju, "Microstructure-texturemechanical properties in hot rolling of a centrifugal casting ring blank," Journal of Materials Engineering and Performance, vol. 25, no. 3, pp. 1237-1248, 2016.

[4] F. Jiang, H. Zhang, J. Su, and Y. Sun, "Constitutive characteristics and microstructure evolution of 7150 aluminum alloy during isothermal and non-isothermal multistage hot compression," Materials Science and Engineering: A, vol. 636, pp. 459-469, 2015.

[5] Q. Lin, W. Dong, Y. Li, H. Zhang, and Z. Wang, "Microstructure simulation of 2519 aluminum alloy in multi-pass hot compression process," Procedia Engineering, vol. 81, pp. 1259-1264, 2014.

[6] X. M. Zhang, J. P. Han, S. D. Liu, X. X. Huang, and J. Liu, "Effect of finishing temperature on microstructure of 7050 aluminum alloy during hot-compression deformation," Journal of Central South University. Science \& Technology, vol. 43, no. 9, pp. 3386-3393, 2012, (in Chinese).

[7] M. Bambach and S. Seuren, "On instabilities of force and grain size predictions in the simulation of multi-pass hot rolling processes," Journal of Materials Processing Technology, vol. 216, pp. 95-113, 2015.

[8] H. F. Zhang, B. Sheng, and H. H. Zhang, "Simulation to the grain evolution of micro alloy steel during multi-pass rolling," Shanghai Metals, vol. 34, no. 6, pp. 43-46, 2012, (in Chinese).

[9] I. Shakhova, Z. Yanushkevich, I. Fedorova, A. Belyakov, and R. Kaibyshev, "Grain refinement in a $\mathrm{Cu}-\mathrm{Cr}-\mathrm{Zr}$ alloy during multidirectional forging," Materials Science and Engineering: A, vol. 606, pp. 380-389, 2014.

[10] Y. T. Li, L. Ju, H. P. Qi, F. Zhang, G. Z. Cheng, and M. L. Wang, "Technology and experiments of 42CrMo bearing ring forming based on casting ring blank," Chinese Journal of Mechanical Engineering, vol. 27, no. 2, pp. 417-427, 2014.

[11] Y. C. Lin, M.-S. Chen, and J. Zhong, "Study of metadynamic recrystallization behaviors in a low alloy steel," Journal of Materials Processing Technology, vol. 209, no. 5, pp. 24772482, 2009.

[12] H. Qi and Y. Li, "Metadynamic Recrystallization of the as-cast $42 \mathrm{CrMo}$ steel after normalizing and tempering during hot compression," Chinese Journal of Mechanical Engineering, vol. 25, no. 5, pp. 853-859, 2012.

[13] Y. C. Lin, F. Wu, Q.-W. Wang, D.-D. Chen, and S. K. Singh, "Microstructural evolution of a $\mathrm{Ni}-\mathrm{Fe}-\mathrm{Cr}$-base superalloy during non-isothermal two-stage hot deformation," Vacuum, vol. 151, pp. 283-293, 2018.

[14] H. Zhang, G. Y. Lin, D. S. Peng, L. B. Yang, and Q. Q. Lin, "Dynamic and static softening behaviors of aluminum alloys during multistage hot deformation," Journal of Materials Processing Technology, vol. 148, no. 2, pp. 245-249, 2004.

[15] K. P. Rao, Y. K. D. V. Prasad, and E. B. Hawbolt, "Study of fractional softening in multi-stage hot deformation," Journal of Materials Processing Technology, vol. 77, no. 1-3, pp. 166174, 1998
[16] J. P. Li, J. Shen, X. D. Yan, B. P. Mao, and L. M. Yan, "Recrystallization behavior of 7050 aluminum alloy during multipass hot compression process," Chinese Journal of Nonferrous Metals, vol. 19, no. 10, pp. 1754-1758, 2009, (in Chinese).

[17] H. Yan, Y. T. Li, Y. Hu, Q. S. Li, D. W. Zhao, and Z. Z. Cao, "Study on the microstructure and mechanical properties of Q235B ring casting blank," Journal of Mechanical Engineering, vol. 50, no. 14, pp. 89-94, 2014, (in Chinese).

[18] F. Qin, Y. Li, H. Qi, and X. Wei, "Microstructure and mechanical properties of as-cast 42CrMo ring blank during hot rolling and subsequent quenching and tempering," Journal of Materials Engineering and Performance, vol. 26, no. 3, pp. 1300-1310, 2017.

[19] F. Qin, Y. Li, H. Qi, and Z. Lv, "Deformation behavior and microstructure evolution of as-cast $42 \mathrm{CrMo}$ alloy in isothermal and non-isothermal compression," Journal of Materials Engineering and Performance, vol. 25, no. 11, pp. 5040-5048, 2016.

[20] G. He, L. Tan, F. Liu, L. Huang, Z. Huang, and L. Jiang, "Revealing the role of strain rate during multi-pass compression in an advanced polycrystalline nickel base superalloy," Materials Characterization, vol. 128, pp. 123-133, 2017.

[21] B. Guo, C. Aranas Jr., A. Foul et al., "Effect of multipass deformation at elevated temperatures on the flow behavior and microstructural evolution in Ti-6Al-4V," Materials Science and Engineering: A, vol. 729, pp. 119-124, 2018.

[22] J. Liu, W. Zeng, Y. Zhu, H. Yu, and Y. Zhao, "Hot deformation behavior and flow stress prediction of TC4-DT alloy in singlephase region and dual-phase regions," Journal of Materials Engineering and Performance, vol. 24, no. 5, pp. 2140-2150, 2015.

[23] J. Fu, Y. T. Li, J. H. Fu et al., "Dynamic recrystallization behavior of as-cast $42 \mathrm{CrMo}$ steel during hot compression deformation," Materials for Mechanical Engineering, vol. 36, no. 2, pp. 91-95, 2012, (in Chinese).

[24] Y. Li, H. P. Qi, J. H. Fu et al., "Theoretical and process analyses on the cast-blank rolling forming of $42 \mathrm{CrMo}$ bearing rings," Journal of Mechanical Engineering, vol. 50, no. 2, pp. 77-85, 2014, (in Chinese).

[25] N. D. Ryan and H. J. Mcqueen, "Bar mill torsional simulation of 304 stainless steel," Canadian Metallurgical Quarterly, vol. 30, no. 2, pp. 113-124, 1991.

[26] J. Luo, J. Gao, L. Li, and M. Q. Li, "The flow behavior and the deformation mechanisms of Ti-6Al-2Zr-2Sn-2Mo-1.5Cr- $2 \mathrm{Nb}$ alloy during isothermal compression," Journal of Alloys and Compounds, vol. 667, pp. 44-52, 2016.

[27] H. J. Mcqueen, "Metal forming: industrial, mechanical computational and microstructural," Journal of Materials Processing Technology, vol. 37, no. 1-4, pp. 3-36, 1993.

[28] N. D. Ryan and H. J. Mcqueen, "Hot strength and microstructural evolution of 316 stainless steel during simulated multistage deformation by torsion," Journal of Materials Processing Technology, vol. 36, no. 2, pp. 103-123, 1993.

[29] N. Radovic and D. Drobnjak, "Effect of interpass time and cooling rate on apparent activation energy for hot working and critical recrystallization temperature of Nb-microalloyed steel," ISIJ International, vol. 39, pp. 575-582, 1999.

[30] Y.-W. Xiao, Y. C. Lin, Y.-Q. Jiang et al., "A dislocation density-based model and processing maps of Ti-55511 alloy with bimodal microstructures during hot compression in $\alpha+\beta$ region," Materials Science and Engineering: A, vol. 790, p. 139692, 2020.

[31] C. M. Sellars and W. J. McTegart, "On the mechanism of hot deformation," Acta Metallurgica, vol. 14, no. 9, pp. 1136-1138, 1966. 
[32] M. Abbasi, M. Naderi, and A. Saeed-Akbari, "Isothermal versus non-isothermal hot compression process: a comparative study on phase transformations and structure-property relationships,” Materials \& Design, vol. 45, pp. 1-5, 2013.

[33] Y. C. Lin, Y.-W. Xiao, Y.-Q. Jiang et al., "Spheroidization and dynamic recrystallization mechanisms of Ti-55511 alloy with bimodal microstructures during hot compression in $\alpha+\beta$ region," Materials Science and Engineering: A, vol. 782, p. 139282, 2020.

[34] E. Evangelista, H. J. McQueen, and N. D. Ryan, "Hot strength, dynamic recovery and dynamic recrystallization of 317 type stainless steel," Metallurgical Science and Technology, vol. 5, no. 2, pp. 50-58, 1987.

[35] N. D. Ryan and H. J. McQueen, "Work hardening, strength and ductility in the hot working of 304 austenitic stainless steel," High Temperature Technology, vol. 8, no. 1, pp. 27-44, 1990.

[36] N. D. Ryan and H. J. McQueen, "Flow stress, dynamic restoration, strain hardening and ductility in hot working of 316 steel," Journal of Materials Processing Technology, vol. 21, no. 2, pp. 177-199, 1990.

[37] A. H. Ucisik, L. Weiss, H. J. McQueen, and J. J. Jonas, "Multistage hot deformation with decreasing temperature of two plain carbon and two HSLA steels," Canadian Metallurgical Quarterly, vol. 19, pp. 351-358, 1981.

[38] N. D. Ryan and H. J. McQueen, Proceedings of the 4th Steel Rolling Congress, B. Fazan, Ed., IRSID, pp. F17.1-F17.9, Mazieres-Le-Metz, France, 1987. 